\title{
Room-temperature vacancy migration in crystalline Si from an ion-implanted surface layer
}

Larsen, Arne Nylandsted; Christensen, Carsten; Petersen, Jon Wulff

Published in:

Journal of Applied Physics

Link to article, DOI:

10.1063/1.371453

Publication date:

1999

Document Version

Publisher's PDF, also known as Version of record

Link back to DTU Orbit

Citation (APA):

Larsen, A. N., Christensen, C., \& Petersen, J. W. (1999). Room-temperature vacancy migration in crystalline Si from an ion-implanted surface layer. Journal of Applied Physics, 86(9), 4861-4864.

https://doi.org/10.1063/1.371453

\section{General rights}

Copyright and moral rights for the publications made accessible in the public portal are retained by the authors and/or other copyright owners and it is a condition of accessing publications that users recognise and abide by the legal requirements associated with these rights.

- Users may download and print one copy of any publication from the public portal for the purpose of private study or research.

- You may not further distribute the material or use it for any profit-making activity or commercial gain

- You may freely distribute the URL identifying the publication in the public portal

If you believe that this document breaches copyright please contact us providing details, and we will remove access to the work immediately and investigate your claim 


\title{
Room-temperature vacancy migration in crystalline Si from an ion-implanted surface layer
}

\author{
Arne Nylandsted Larsen ${ }^{\text {a) }}$ \\ Institute of Physics and Astronomy, University of Aarhus, DK-8000 Aarhus C, Denmark \\ Carsten Christensen and Jon Wulff Petersen \\ Mikroelektronik Centret, The Technical University of Denmark, DK-2800 Lyngby, Denmark
}

(Received 29 March 1999; accepted for publication 30 July 1999)

\begin{abstract}
Migration of vacancies in crystalline, $n$-type silicon at room temperature from $\mathrm{Ge}^{+}$-implanted $(150$ $\left.\mathrm{keV}, 5 \times 10^{9}-1 \times 10^{11} \mathrm{~cm}^{-2}\right)$ surface layers was studied by tracing the presence of $\mathrm{P}-\mathrm{V}$ pairs $(E$ centers) in the underlying layer using deep level transient spectroscopy (DLTS). Under the conditions we have examined, the vacancies migrate to a maximum depth of about $1 \mu \mathrm{m}$ and at least one vacancy per implanted Ge ion migrates into the silicon crystal. The annealing of the $E$ centers is accompanied, in an almost one-to-one fashion, by the appearance of a new DLTS line corresponding to a level at $E_{C}-E_{t} \approx 0.15 \mathrm{eV}$ that has donor character. It is argued that the center associated with this line is most probably the $\mathrm{P}_{2}-\mathrm{V}$ complex; it anneals at about $550 \mathrm{~K}$. A lower limit of the RT-diffusion coefficient of the doubly charged, negative vacancy is estimated to be 4 $\times 10^{-11} \mathrm{~cm}^{2} / \mathrm{s}$. (C) 1999 American Institute of Physics. [S0021-8979(99)05421-3]
\end{abstract}

\section{INTRODUCTION}

Ion implantation into the outermost surface layer of a silicon single crystal held at room temperature (RT) has recently been demonstrated to give rise to migration of point defects into the silicon crystal from the ion implanted layers. ${ }^{1-3}$ Both vacancies and interstitials have been demonstrated to migrate, by appearance of phosphorus-vacancy pairs ( $\mathrm{P}-\mathrm{V}$ pairs or $E$ centers) in deeper lying layers ${ }^{1}$ and by reduction of already existing vacancy-type defects, ${ }^{3}$ respectively. Thus, these experiments demonstrate that both vacancies and self interstitials are mobile at room temperature. Estimates of the RT-diffusion coefficients of the point defects were obtained from the experiments: from phosphorusdeactivation profiles measured by spreading resistance of $n$-type $\mathrm{Si}$, a lower limit of $\sim 4 \times 10^{-11} \mathrm{~cm}^{2} / \mathrm{s}$ (Ref. 2) was estimated for the diffusion coefficient of self-interstitials, and from in situ measurements of leakage-current reduction values of $1.5 \times 10^{-15}$ and $3.0 \times 10^{-13} \mathrm{~cm}^{2} / \mathrm{s}$ for interstitials and vacancies, respectively, were determined. ${ }^{3}$

The observation that the point defects are mobile at room temperature is in agreement with extrapolations to room temperature of results from low temperature irradiation experiments; ${ }^{4}$ for the neutral vacancy, a RT value of $\sim 5$ $\times 10^{-10} \mathrm{~cm}^{2} / \mathrm{s}$ (Refs. 5 and 6) was estimated in this way. Extra polation to RT of point-defect diffusion coefficients estimated at high temperature from diffusion experiments leads to very uncertain values as the high temperature pointdefect diffusion coefficients are already uncertain; in general these extrapolations give rather small RT-diffusion coefficients which could not give rise to any measurable diffusion at room temperature. ${ }^{6}$ Recent molecular-dynamics simulations of point-defect diffusion in $\mathrm{Si}^{4,7}$ have given RTdiffusion coefficients which for the neutral vacancy agrees

${ }^{a)}$ Corresponding author; electronic mail: anl@ifa.au.dk well with the above estimates $\left(D_{\mathrm{v}} \approx 2 \times 10^{-11} \mathrm{~cm}^{2} / \mathrm{s}\right)$ but which for the neutral self-interstitial is somewhat smaller $\left(D_{I} \approx 4 \times 10^{-18} \mathrm{~cm}^{2} / \mathrm{s}\right)$. It should be noted, however, that the point defects can be differently charged depending on the position of the Fermi level; this is known to have a strong influence on the temperature at which they become mobile after low-temperature irradiations. ${ }^{8}$

It has recently been argued by Privitera and co-workers ${ }^{2,4}$ that the observed electrical deactivation to large depths of phosphorus dopants in $n$-type $\mathrm{Si}$ after shallow RT ion implantations, was due to an interaction with Si selfinterstitials and not with vacancies; the above quoted lower limit of the self-interstitial diffusion coefficient of $\sim 4$ $\times 10^{-11} \mathrm{~cm}^{2} / \mathrm{s}$ (Ref. 2) was estimated under this assumption. A major argument behind this conclusion was the observation that the electrical deactivation was stable above $200{ }^{\circ} \mathrm{C}$ which is a temperature where the $\mathrm{P}-\mathrm{V}$ pairs have annealed ${ }^{8}$ (the $\mathrm{P}-\mathrm{V}$ pair is expected to be the complex responsible for a vacancy-assisted deactivation of the electrical activity). In the present report, however, we will demonstrate that the observed dopant deactivation is in agreement with the formation of $\mathrm{P}-\mathrm{V}$ pairs. The observed stability of the deactivation above $200^{\circ} \mathrm{C}$, when the $\mathrm{P}-\mathrm{V}$ pairs anneal, is explained as being due to the formation of a new donor center in an almost one-to-one ratio with the disappearence of the $\mathrm{P}-\mathrm{V}$ pairs. Our estimate of the lower limit of the RT vacancydiffusion coefficient from the in-growth of the $\mathrm{P}-\mathrm{V}$ pairs after ion implantation is $4 \times 10^{-11} \mathrm{~cm}^{2} / \mathrm{s}$, a value which is similar to the above estimate of the lower limit of the selfinterstitial diffusion coefficient at room temperature from the observed deactivation of phosphorus.

\section{EXPERIMENTAL PROCEDURE}

The presence of the $\mathrm{P}-\mathrm{V}$ pairs in $n$-type $\mathrm{Si}$ after ion implantation was, in the present investigation, monitored by 


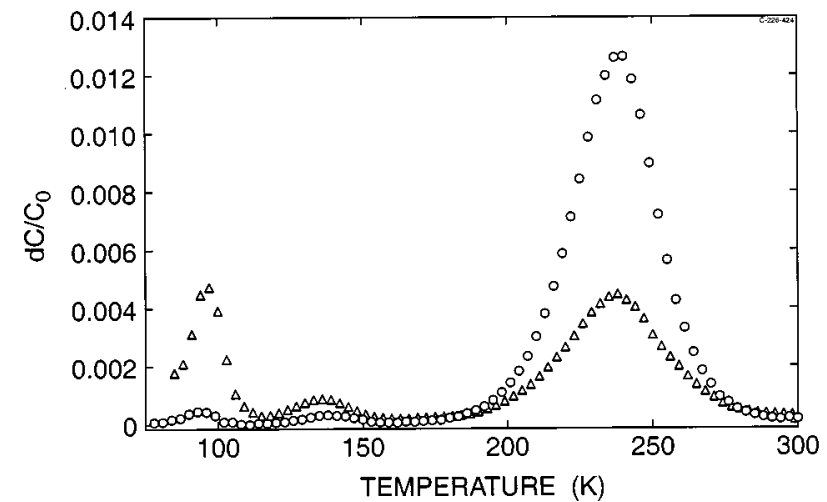

FIG. 1. DLTS spectra of a $p^{+} n$-mesa diode implanted at room temperature with $150 \mathrm{keV} \mathrm{Ge}^{+}$ions to a dose of $1 \times 10^{10} \mathrm{~cm}^{-2}$, before $(\bigcirc)$ and after $(\triangle)$ a reverse bias annealing at $380 \mathrm{~K}$ for $60 \mathrm{~min}$ at a reverse bias of $-10 \mathrm{~V}$. Only every third data point is shown. The DLTS spectrum was measured by pulsing from -5 to $0 \mathrm{~V}$ with a repetition rate of $250 \mathrm{~Hz}$ and a pulse width of $150 \mu \mathrm{s}$.

deep level transient spectroscopy (DLTS) via its acceptor level at $E_{C}-E_{\mathrm{PV}}=0.42 \mathrm{eV},{ }^{8}$ where $E_{C}$ is the energy of the bottom of the conduction band. Both $p^{+} n$-mesa diodes, and $\mathrm{Au}$ and Pt Schottky diodes were utilized. The mesa diodes were formed from (100)-oriented, $\sim 2 \quad \Omega \mathrm{cm} \quad(2.5$ $\left.\times 10^{15} \mathrm{P} / \mathrm{cm}^{3}\right), n$-type, FZ-type Si wafers with a $2000 \AA$ thick, molecular beam epitaxially (MBE) grown, highly boron-doped $\left(\sim 5 \times 10^{19} \mathrm{~B} / \mathrm{cm}^{3}\right) p^{+}$top layer. Into these diodes $150 \mathrm{keV}$ Ge ions were implanted to doses between 5 $\times 10^{9}$ and $1 \times 10^{11} \mathrm{~cm}^{-2}$ with the samples tilted by $7^{\circ}$ relative to the beam direction in order to reduce channeling effects. The lower and upper dose limits were determined by the minimum dose which we could handle in our implantation system and by the DLTS demand of a P-V concentration less than $10 \%$ of the dopant concentration, respectively. Both the Ge and the defect distributions are completely contained within the $p^{+}$top layers, according to TRIM simulations. ${ }^{9}$ Gold-Schottky diodes were also formed (using thermal evaporation of $\mathrm{Au}$ ) on $1 \Omega \mathrm{cm} n$-type, FZ-Si in which the Ge implantation had been done prior to the diode formation. Further, some results of defect introduction from Pt Schottky-diode formation by e-gun evaporation of Pt on 1 $\Omega \mathrm{cm}, n$-type, FZ-Si will be presented. We have previously demonstrated that an e-gun evaporation of, e.g., Pt is accompanied with a bombardment of low energy ions giving rise to an injection of vacancies identical to the one observed in an ion implantation process. ${ }^{1}$ Finally, for reference purposes, 2 $\mathrm{MeV}$ electron irradiations were done in both FZ- and CZtype Si mesa diodes.

\section{RESULTS AND DISCUSSION}

Typical DLTS spectra of a mesa diode ion implanted with $150 \mathrm{keV}$ Ge to a dose of $1 \times 10^{10} \mathrm{~cm}^{-2}$ are shown in Fig. 1, before and after an annealing at $380 \mathrm{~K}$. The spectrum of the as-implanted diode contains one dominating peak at a temperature of $240 \mathrm{~K}$ and two just discernable peaks at temperatures of 95 and $135 \mathrm{~K}$. From Arrhenius plots of the electron emissivity versus reciprocal temperature, ionization enthalpies and apparent capture cross sections (the "DLTS
TABLE I. DLTS signatures from as-implanted mesa diodes: Ionization enthalpies $E_{C}-E_{t}$, relative to the bottom of the conduction band, and apparent capture cross sections $\sigma_{a}$ extracted from Arrhenius plots of the electron emissitivity, corrected for the $T^{2}$ dependence vs reciprocal temperature. The quoted uncertainties are standard error of the means from a large number of measurements.

\begin{tabular}{ccc}
\hline \hline Temperature of & & \\
DLTS line $(\mathrm{K})$ & $E_{C}-E_{t}(\mathrm{eV})$ & $\sigma_{a}\left(\mathrm{~cm}^{2}\right)$ \\
\hline 95 & $\sim 0.13$ & \\
135 & $\sim 0.24$ & \\
240 & $0.415 \pm 0.003$ & $(2.0 \pm 0.4) \times 10^{-15}$ \\
\hline \hline
\end{tabular}

signatures") have been extracted; they are collected in Table I. The extracted parameters for the dominating line is in perfect agreement with those for the $E$ center in $\mathrm{Si}$ found in the electron irradiated FZ-Si mesa diodes, and we conclude that this line originates from $E$ centers. The parameters of the two small lines are uncertain due to their small intensities; however, the ionization enthalpy of the line at $135 \mathrm{~K}$ is in agreement with that of the di-vacancy, ${ }^{8}$ whereas that of the line at $95 \mathrm{~K}$ is smaller than that of the interstitial oxygen-vacancy pair $(\mathrm{O}-\mathrm{V}$ or $A$ center) [the $A$ center is typically found in $\mathrm{CZ}$-type $\mathrm{Si}$ after $\mathrm{MeV}$-electron irradiation with an ionization enthalpy of $E_{C}-E_{A}=0.16 \mathrm{eV}$ (Ref. 8)].

The depth profile of the $E$ centers is shown in Fig. 2 measured by the double-pulse DLTS technique. It appears that the $E$-center distribution extends to a depth of about 1 $\mu \mathrm{m}$ and peaks towards the surface. Thus, vacancies migrating from the ion implanted surface layer into the Si crystal interact predominantly with $\mathrm{P}^{+}$ions to form $E$ centers and, to a much lesser extent, with each other to form di-vacancies. The depth distribution shown in Fig. 2 is most probably determined by the interaction of the migrating vacancies with $\mathrm{P}^{+}$ions (trap-limited migration) and not by the vacancydiffusion coefficient, as discussed in Ref. 2. The depth region from 0 to $\sim 0.3 \mu \mathrm{m}$ of Fig. 2 is the depletion region of the mesa diode. The charge state of the migrating vacancies in this region depends on the position of the $(0 /-)$-acceptor level of the vacancy in the band gap; as this level is probably situated in the middle of the gap ${ }^{8}$ both neutral and singly

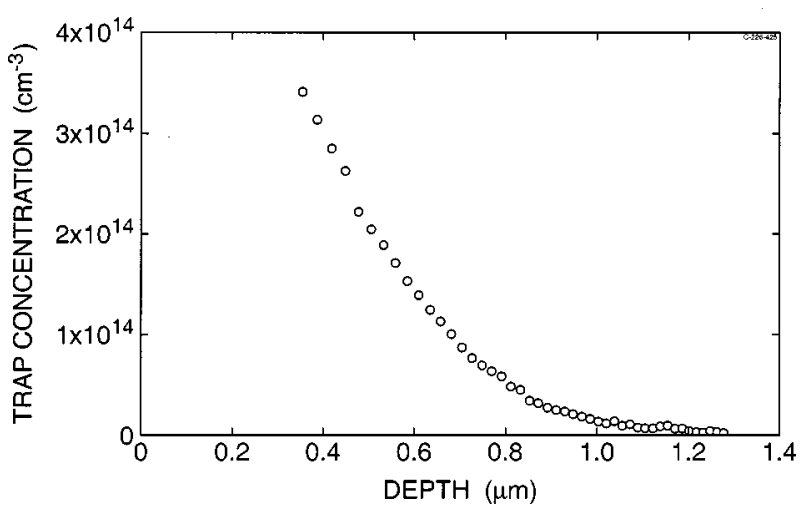

FIG. 2. Depth profile of the $E$ center of a $p^{+} n$-mesa diode implanted with $150 \mathrm{keV} \mathrm{Ge}{ }^{+}$ions to a dose of $1 \times 10^{10} \mathrm{~cm}^{-2}$ measured with the double pulse DLTS technique using $\Delta U=0.5 \mathrm{~V}$ corresponding to a depth resolution of $\sim 600 \AA$. 
charged negative vacancies can be assumed in this region. In the field-free region of the diode, from $\sim 0.3 \mu \mathrm{m}$ and further in, the charge state of the vacancy is either singly or doubly negative depending on the position of the $(-/=)$-acceptor level of the vacancy. If this level is situated at $0.28 \mathrm{eV}$ from the conduction band as suggested in Ref. 10, a major fraction of the migrating vacancies will be doubly negative charged. Thus, the interaction between vacancies and $\mathrm{P}^{+}$ions will be strongest in the field-free region, and the profile can be anticipated to somehow level-off towards the surface. These considerations are in agreement with $\mathrm{P}-\mathrm{V}$ profiles measured in Schottky diodes where the diode is formed after ion implantation and where, consequently, the vacancies have migrated all the way in a field free region. In this case fewer $\mathrm{P}-\mathrm{V}$ pairs are found compared to those in the mesa diodes at similar depths indicating that more vacancies have been trapped in the near surface layer. An integration of the profile of Fig. 2 yields a total $\mathrm{P}-\mathrm{V}$ concentration of 1 $\times 10^{10} \mathrm{~cm}^{-2}$. As the implanted dose was also 1 $\times 10^{10} \mathrm{~cm}^{-2}$, and considering the above discussion on the shape of the $\mathrm{P}-\mathrm{V}$ profile in the depletion layer, it can be concluded that at least one vacancy is injected per implanted Ge ion; similar values were found in the whole dose range investigated. This value is much higher than the value of $\sim 10^{-4}$ which Privitera et al. ${ }^{4}$ found from the $P$-deactivation experiments after $40 \mathrm{keV} \mathrm{Si}$ implantations to doses in the $10^{13} \mathrm{~cm}^{-2}$ range. However, Privitera et al. observed an increasing value with decreasing dose, probably reflecting the increase in complexity of the damage with increasing dose and, hence, an increasing trapping of the point defects in the damage, as also discussed by Privitera et al.

Also shown in Fig. 1 is a DLTS spectrum of the mesa diode after a reverse-bias annealing at $380 \mathrm{~K}$ for $60 \mathrm{~min}$. The annealing results in a significant reduction of the intensity of the $E$-center line, a slight increase of the di-vacancy line, and a large increase of the small line at $95 \mathrm{~K}$. It is well established that both the $\mathrm{O}_{i}-\mathrm{V}$ pair and the $\mathrm{C}_{i}-\mathrm{C}_{s}$ pair have characteristic DLTS lines at or near $95 \mathrm{~K}$ (Ref. 8) for the present measuring conditions. However, only small $\mathrm{C}$ and $\mathrm{O}$ concentrations are expected in these crystals and, in addition, no characteristic $\mathrm{C}_{i}$ line was observed at lower temperature prior to the appearance of this new line $\left(\mathrm{C}_{i}\right.$ is produced in irradiation experiments by the $\mathrm{Si}_{i}+\mathrm{C}_{s} \rightarrow \mathrm{C}_{i}$ replacement mechanism; it becomes mobile at about $320 \mathrm{~K}$ and transforms into the $\mathrm{C}_{i}-\mathrm{C}_{s}$ pair ${ }^{8}$ ). Thus, $\mathrm{C}_{i}-\mathrm{C}_{s}$ is excluded as the cause of this new line. The electron emission from the center associated to this line is strongly dependent on the electric field (the emission shows Poole-Frenkel effect ${ }^{8}$ ); this is not a diode artifact as demonstrated in Fig. 3 where the electron emissivity is displayed versus the electric field for both the $E$ center and the new center measured in the same diode: the emission rate of the new center increases with increasing electric field whereas that of the $E$ center is independent of the field as it should be for electron emission from the $(0 /$ -)-acceptor level of the $E$ center. A similar analysis of the $A$ center produced in CZ-type $\mathrm{Si}$ after a $2 \mathrm{MeV}$ electron irradiation (not shown) gives also an electric-field-independent emission rate, as expected as this $A$-center level is known to be a $(0 /-)$-acceptor level. Thus, we conclude that the new

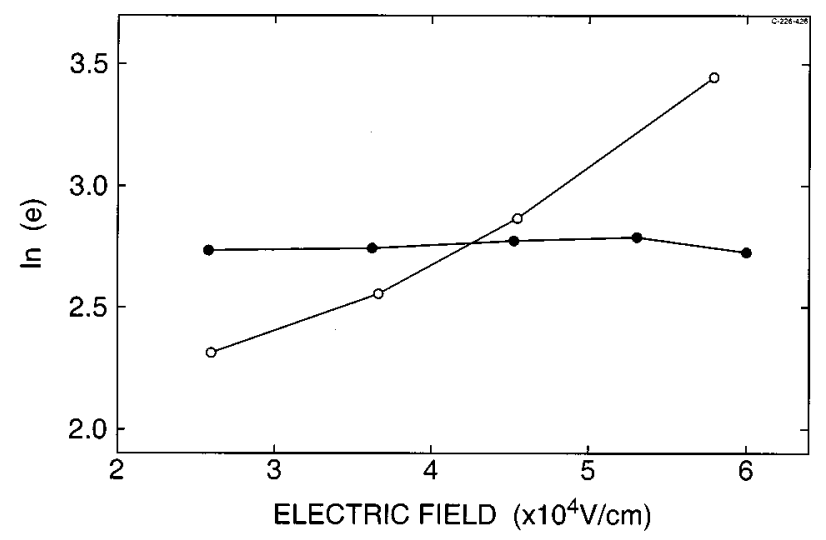

FIG. 3. Electron-emission rate vs electric field of the (0/-)-acceptor level of the $E$ center $(\bullet)$ and the $E_{C}-E_{t} \approx 0.15 \mathrm{eV}$ level of the new center $(\bigcirc)$ measured in a $p^{+} n$-mesa diode implanted with $150 \mathrm{keV} \mathrm{Ge}{ }^{+}$ions to a dose of $1 \times 10^{10} \mathrm{~cm}^{-2}$ annealed at $450 \mathrm{~K}$ for $30 \mathrm{~min}$. The new defect line was measured at a temperature of $93 \mathrm{~K}$ and the $E$-center line at $227 \mathrm{~K}$.

center is not the $A$-center and, furthermore, that the level under investigation is a donor level. Curves like the one shown in Fig. 3 for the new line have been measured at different temperatures and the emission rate at zero field have been estimated. These values were plotted versus reciprocal temperature and the ionization enthalpy extracted from the slope of this Arrhenius plot was found to be $E_{C}-E_{t}$ $=(0.15 \pm 0.02) \mathrm{eV}$; (for the $A$ center in the electronirradiated CZ-Si mesa diodes, we find $E_{C}-E_{A}=(0.16$ $\pm 0.01) \mathrm{eV}$.

The new line grows in according to an almost one-to-one ratio with the disappearance of the $E$ center, as demonstrated in Fig. 4. However, one should be cautious about this oneto-one ratio as the $E$-center distribution in the depletion layer of the diode might interact with the $E$-center distribution in the field-free region during annealing. In the experimental situation of Fig. 4, the $E$-center concentration is expected to be higher in the depletion region than in the field-free region as part of the vacancy in-diffusion has taken place without the presence of a depletion layer (the depletion layer develops during the e-gun deposition). Thus, a certain in-diffusion

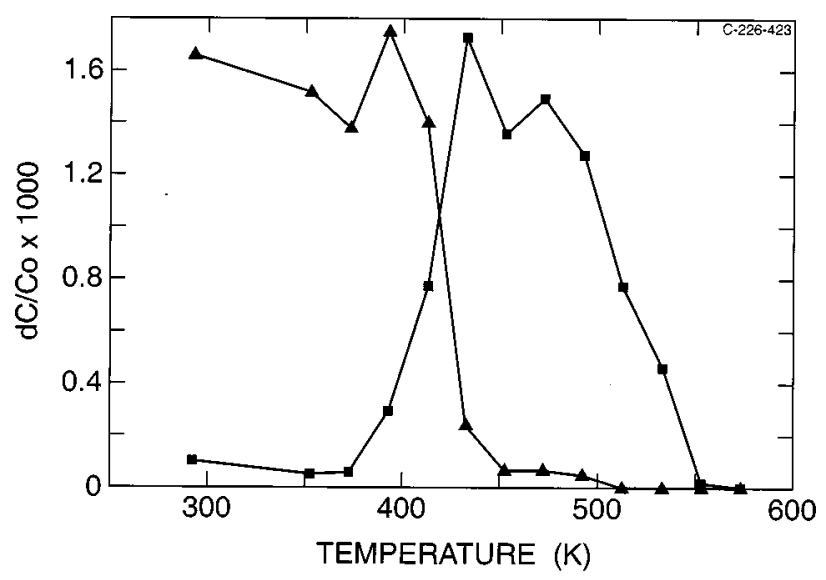

FIG. 4. DLTS intensities of the $E$-center line $(\boldsymbol{\Delta})$ and the new line $(\boldsymbol{\square})$ as a function of anneal temperature for a $30 \mathrm{~min}$ isochronal annealing. The diode was a Pt Schottky diode in which the Pt had been e-gun evaporated (see Ref. 1). The spectrum was measured with a repetition rate of $250 \mathrm{~Hz}$. 
of $E$ centers from the depletion layer into the field-free region might be anticipated during annealing and the almost exact one-to-one ratio of Fig. 4 is most probably a coincidence; in ion-implanted mesa diodes conversion ratios of $70 \%$ are typically found. The new center has completely annealed at a temperature of $550 \mathrm{~K}$ [this is also the anneal temperature of the $\mathrm{C}_{i}-\mathrm{C}_{s}$ pair whereas the $A$ center anneals at about $650 \mathrm{~K}$ (Ref. 8)].

There are two serious candidates to the center associated to this new DLTS line, namely, the $\mathrm{P}_{2}-\mathrm{V}$ and $\mathrm{P}-\mathrm{V}_{2}$ centers. In the field-free region of the diodes, which is the region under investigation, the only defects, prior to the annealing, of any significant concentrations are the $\mathrm{P}^{+}$ions and the negatively charged $\mathrm{P}-\mathrm{V}$ pairs; thus, it will be natural to look for candidates among combinations of these defects. It can be concluded from the small growth of the di-vacancy during annealing (Fig. 1) that part of the $E$ centers dissociates during annealing. Whether they all disintegrate or only a small fraction does we cannot decisively conclude from the present experiments. Previous investigations of the annealing of the $E$ center favor the diffusion to traps as the main cause of the disappearance of the $E$ center during annealing with some additional annealing due to other defect reactions. ${ }^{11-13} \mathrm{~A}$ trapping of mobile, probably neutral, ${ }^{14} \mathrm{P}-\mathrm{V}$ pairs by already existing $\mathrm{P}^{+}$ions would then lead to $\mathrm{P}_{2}-\mathrm{V}$ centers and can in a straightforward way explain the observed very high conversion efficiency of $70 \%-100 \%$ as only one $\mathrm{P}-\mathrm{V}$ pair is needed for this reaction. The $\mathrm{P}_{2}-\mathrm{V}$ center has previously been argued to be responsible for the NL1 spectrum observed by Sieverts and Ammerlaan ${ }^{15}$ in electronparamagnetic resonance (EPR) studies of electron-irradiated silicon containing high phosphorus concentrations. A formation of $\mathrm{P}-\mathrm{V}_{2}$ centers by trapping of mobile, negatively charged vacancies by stationary, negatively charged $\mathrm{P}-\mathrm{V}$ pairs seems less probable from a Coulomb-repulsion argument. It would also demand a high degree of dissociation of the $\mathrm{P}-\mathrm{V}$ pairs during annealing as they are the only source of vacancies; because of that a conversion efficiency of at most $50 \%$ could be expected. Thus, we favor the $\mathrm{P}_{2}-\mathrm{V}$ complex as the center associated to the new line. As its level, situated at $E_{C}-E_{t}=0.15 \mathrm{eV}$, is a donor level it will be fully ionized at room temperature. However, because it includes two $\mathrm{P}$ atoms it will nevertheless deactivate the $\mathrm{P}$ dopants to almost the same degree $(70 \%-100 \%)$ as the neutral $E$ centers do. This is then most probably the explanation as to why Kyllesbech Larsen $e t$ al. $^{2}$ observed that the electrical de-activation of the P dopants was stable above the anneal temperature of the $E$ center.

An obvious question to be asked is whether $\mathrm{P}_{2}-\mathrm{V}$ complexes are also formed when $E$ centers, formed by $\mathrm{MeV}$ electron irradiation, anneal. This point has been only briefly addressed in the present investigation, and only in the case of FZ Si. It is found that a small fraction of the annealing $E$ centers converts into $\mathrm{P}_{2}-\mathrm{V}$ complexes, however, the predominant fraction of the $E$ centers simply disappear without the appearance of a new complex. We speculate that interstitial-type defects produced in the irradiation process participate in this annealing process.
We have estimated a lower limit for the vacancydiffusion coefficient at RT by performing the DLTS measurement as soon as possible after a Ge-ion implantation of a mesa diode to a dose of $1 \times 10^{10} \mathrm{~cm}^{-2}$. The ion implantation itself took $45 \mathrm{~s}$ and $4 \mathrm{~min}$ after the finishing of the ion implantation the measurement of the intensity of the DLTS $E$ center line was performed. It was found that already at that time the $E$-center-DLTS line had achieved its full intensity and the $E$-center-depth profile its final form. Thus, from this measurement we can only make an estimate of the lower bound of the vacancy-diffusion coefficient at room temperature of $\sim 4 \times 10^{-11} \mathrm{~cm}^{2} / \mathrm{s}$ which is then for the vacancy being predominantly doubly negatively charged. This charge state of the vacancy is known from low temperature irradiation experiments to be more mobile than the neutral charge state. ${ }^{8}$

\section{CONCLUSION}

In summary, we have demonstrated that following a Ge ion implantation to a low dose of the outermost surface layer of a $n$-type FZ-silicon single crystal, a large number of vacancies migrate deep into the Si crystal where they interact with $\mathrm{P}^{+}$ions to form $\mathrm{P}-\mathrm{V}$ pairs. When the $\mathrm{P}-\mathrm{V}$ pairs anneal a new DLTS line appear in an almost one-to-one fashion with the disappearance of the $\mathrm{P}-\mathrm{V}$ pairs; the corresponding level is situated at $E_{C}-E_{t}=0.15 \mathrm{eV}$ and shows donor character. We argue that the defect associated to this new line is most probably the $P_{2}-V$ complex. From these experiments, a lower limit of the RT-diffusion coefficient of the doubly charged, negative vacancy is estimated to be 4 $\times 10^{-11} \mathrm{~cm}^{2} / \mathrm{s}$.

\section{ACKNOWLEDGMENTS}

Thanks are due to Pia Bomholt for the preparation of numerous diodes and to N. E. B. Cowern, Philips, Eindhoven for valuable discussions. This work was supported by the Danish Natural Scientific Research Council.

${ }^{1}$ C. Christensen, J. Wulff Petersen, and A. Nylandsted Larsen, Appl. Phys. Lett. 51, 1426 (1992).

${ }^{2}$ K. Kyllesbech Larsen, V. Privitera, S. Coffa, F. Priolo, S. U. Campisano, and A. Carnera, Phys. Rev. Lett. 76, 1493 (1996).

${ }^{3}$ S. Coffa and S. Libertino, Appl. Phys. Lett. 73, 3369 (1998).

${ }^{4}$ See, e.g., V. Privitera, S. Coffa, F. Priolo, and E. Rimini, Riv. Nuovo Cimento 21, 1 (1998), and references therein.

${ }^{5}$ G. D. Watkins, J. Phys. Soc. Jpn. 18, 22 (1963).

${ }^{6}$ J. A. Van Vechten, Phys. Rev. B 10, 1482 (1974).

${ }^{7}$ G. H. Gilmer, T. Diaz De La Rubia, D. M. Stock, and M. Jaraiz, Nucl. Instrum. Methods Phys. Res. B 102, 247 (1995).

${ }^{8}$ G. D. Watkins, in Electronic Structure and Properties of Semiconductors, edited by W. Schröter, Materials Science and Technology, a Comprehensive Treatment (VCH, Weinheim, 1991), Vol. 4, p. 105.

${ }^{9}$ Transport of Ions in Matter, version 95; J. P. Biersack and L. G. Haggmark, Nucl. Instrum. Methods 174, 257 (1980).

${ }^{10}$ C. V. Budtz-Jørgensen, P. Kringhøj, A. Nylandsted Larsen, and N. V. Abrosimov, Phys. Rev. B 58, 1110 (1998).

${ }^{11}$ G. D. Watkins and J. W. Corbett, Phys. Rev. 5A, 1359 (1964).

${ }^{12}$ L. C. Kimerling, H. M. DeAngelis, and J. W. Diebold, Solid State Commun. 16, 171 (1975).

${ }^{13}$ A. O. Evwaraye, J. Appl. Phys. 48, 734 (1977).

${ }^{14}$ Annealing experiments on irradiation-induced $E$-centers have indicated that they diffuse to sinks in their neutral charge state (See Refs. 11-13).

${ }^{15}$ E. G. Sieverts and C. A. J. Ammerlaan, Inst. Phys. Conf. Ser. 31, 213 (1977). 